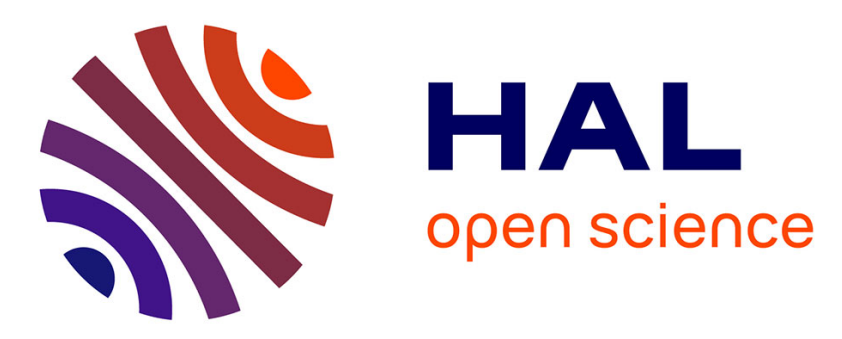

\title{
Unusual swelling of acrylate based crosslinked polymer networks in linear primary alcohols: Experimental and modeling aspects
}

Sofiane Bedjaoui, Lamia Bedjaoui, Mohammed-El-Amine Benbekeda, Frédéric

Dubois, Dounya Merah, Philippe Supiot, Corinne Foissac, Ulrich Maschke

\section{To cite this version:}

Sofiane Bedjaoui, Lamia Bedjaoui, Mohammed-El-Amine Benbekeda, Frédéric Dubois, Dounya Merah, et al.. Unusual swelling of acrylate based crosslinked polymer networks in linear primary alcohols: Experimental and modeling aspects. Journal of Molecular Liquids, 2020, 320 (Part B), pp.114459. 10.1016/j.molliq.2020.114459 . hal-03104372

\section{HAL Id: hal-03104372 \\ https://hal.univ-lille.fr/hal-03104372}

Submitted on 8 Jan 2021

HAL is a multi-disciplinary open access archive for the deposit and dissemination of scientific research documents, whether they are published or not. The documents may come from teaching and research institutions in France or abroad, or from public or private research centers.
L'archive ouverte pluridisciplinaire HAL, est destinée au dépôt et à la diffusion de documents scientifiques de niveau recherche, publiés ou non, émanant des établissements d'enseignement et de recherche français ou étrangers, des laboratoires publics ou privés. 


\section{Unusual swelling of acrylate based crosslinked polymer networks in linear primary alcohols: experimental and modeling aspects}

Sofiane Bedjaoui ${ }^{1,2,3}$, Lamia Bedjaoui ${ }^{2}$, Mohammed El Amine Benbekeda ${ }^{1,2}$, Frédéric Dubois ${ }^{4}$, Dounya Merah ${ }^{2}$, Philippe Supiot ${ }^{1}$, Corinne Foissac ${ }^{1}$, and Ulrich Maschke ${ }^{1 *}$

${ }^{1}$ Unité Matériaux et Transformations - UMET (UMR CNRS Nº8207), Bâtiment C6, Université de Lille - Sciences et Technologies, 59655 Villeneuve d'Ascq Cedex, France

${ }^{2}$ Laboratoire de Recherche sur les Macromolécules (LRM), Faculté des Sciences, Université AbouBekr Belkaïd de Tlemcen (UABB), BP 119, 13000 Tlemcen, Algeria

${ }^{3}$ Département Génie Mécanique, Faculté de Technologie, Université Tahri Mohammed de Béchar (UTMB), BP 417, 08000 Béchar, Algeria

${ }^{4}$ Unité de Dynamique et Structure des Matériaux Moléculaires (UDSMM), Université du Littoral - Côte d'Opale (ULCO), 62228 Calais Cedex, France

E-mail : ulrich.maschke@univ-lille.fr 


\begin{abstract}
The present investigation focuses on analysis of swelling behavior of systems composed of linear primary alcohols and photo-chemically crosslinked poly (butyl prop-2-enoate) (PABu). For this purpose, reactive blends composed of monofunctional (n-ABu) and difunctional (1prop-2-enoyloxyhexyl prop-2-enoate) monomers as well as a standard photoinitiator were exposed to ultraviolet-visible (UV-vis) irradiation to induce free radical crosslinking polymerization. Experimental swelling studies of the obtained optically transparent PABu networks in methanol, ethanol, propan-1-ol, butan-1-ol, pentan-1-ol, hexan-1-ol and heptan-1ol were performed by gravimetric sorption measurements. Among the various models available to rationalize the swelling kinetics of these PABu-alcohol systems, the second order approach was found to agree well with the experimental data.

In particular it was observed that swelling properties strongly depend on the length of the linear alkyl chain of the primary alcohols. Swelling of PABu network at equilibrium increases from methanol to butan-1-ol where it reaches a maximum and subsequently decreases from butan-1-ol to heptan-1-ol. To understand this unusual behavior, polymer-solvent solubility parameters were considered, which could not account for the swelling maximum detected in the case of butan-1-ol. Molecular simulations performed on model systems composed of a linear primary alcohol molecule set and a reproduced PABu network revealed that their mutual interaction energy times the molar mass of the alcohol show a trend very similar to that of the observed swelling behavior.
\end{abstract}

Keywords : Polyacrylate network; crosslinking; swelling; linear primary alcohols; solubility parameters; molecular simulation. 


\section{Introduction}

Polymer gels represent slightly three-dimensional crosslinked networks capable of absorbing and retaining large amounts of solvent while remaining insoluble in solutions [1-6]. The solvent content in a polymer gel may be very high, reaching 100 times or more the polymer weight depending on its affinity with the network. Such gels may be formed by various techniques; however one of the most common synthetic methods is the free radical crosslinking polymerization of reactive monomers in the presence of a crosslinking agent [710]. The polymer gel exhibits solid-like properties due to the network formed by the crosslinking reaction, or more like elastic solids in the sense that there exists a remembered reference configuration to which the gel returns after being deformed for a long time. The most characteristic property of polymeric gel is that it swells in the presence of a solvent and shrinks in its absence. The knowledge of swelling properties of polymer networks in solvents is of significant importance for various applications such as thin polymer films [11,12], adsorption of chemical materials [13], biophotonics [14] and printing [15], superabsorbent polymers and hydrogels [16-19], actuators [20], memory shaped polymers [21,22], porous organic material [23] and gel-based drug delivery systems [24-28]. Predominantly, hydrophilicity/hydrophobicity as well as the nature of polymer chains and solvent, sample preparation, crosslinking density and temperature control the swelling extent.

In the framework of our research, T. Bouchaour et al. [29] established phase diagrams for chemically crosslinked polymer networks swollen in isotropic organic solvents like propan-2one, cyclohexane, methanol, oxolane, and toluene. It was found that the uptake of methanol was very low, whereas the swelling degree for oxolane and toluene reached maximum values at room temperature and also, Flory-Huggins interaction parameters [30] were deduced from this analysis. Vendamme et al. [31] investigated swelling characteristics of polymer networks exhibiting different crosslinking degrees in nematic and smectic liquid crystalline solvents. 
More recently, comparison of the swelling effect with different organic solvents was reported by Ferrell et al. [32].

In this report, swelling properties of a photochemically crosslinked polymer network in linear primary alcohols were investigated. Because of its high optical transparency, toughness, light resistance, stability and chemical inertness, crosslinked Poly (butyl prop-2-enoate) (PABu) was chosen as model system to investigate the effect of alkyl chain length of low molar weight mono-alcohols on the swelling behavior of the network.

The first part of this research was dedicated to perform swelling measurements of photopolymerized crosslinked $\mathrm{PABu}$ networks in primary alcohols i.e. methanol, ethanol, propan-1-ol, butan-1-ol, pentan-1-ol, hexan-1-ol and heptan-1-ol. In the second part, the swelling kinetics of these polymer/solvent systems were analyzed. In particular, an attempt was made to rationalize equilibrium swelling data on the basis of solubility parameters evaluated from Hansen [33-35] and Fedors [36] models, and the corresponding results were discussed accordingly. Finally molecular simulations were carried out to investigate the role of intermolecular interactions of the examined polymer network/alcohol systems.

\section{Experimental}

\subsection{Materials}

The monofunctional butyl prop-2-enoate $(\mathrm{ABu})$ monomer was obtained from Sigma-Aldrich (Saint-Quentin Fallavier, France). The crosslinking agent, 6-prop-2-enoyloxyhexyl prop-2enoate, called HDDA, was supplied by Cray Valley (France). To initiate the free radical photopolymerization/crosslinking reactions, 2-Hydroxy-2-Methyl-1-phenyl-propan-1-one, known as Darocur 1173, supplied by BASF, was used. Various organic solvents (see Table S1 (supplementary material) for the list of the solvents) including linear primary alcohols were purchased from Sigma Aldrich (p.a. grade solvents). All these reagents were used as 
received.

a)<smiles>C=CC(=O)OCCCC</smiles>

b)<smiles>C=CC(=O)OCCCCCCOC(=O)C=C</smiles>

c)

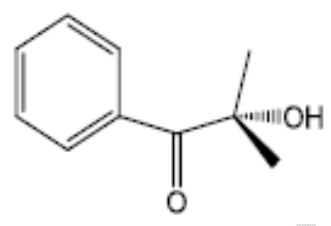

Figure 1: Chemical structures of (a) butyl prop-2-enoate ( $\mathrm{BBu}$ ), (b) 6-prop-2-enoyloxyhexyl prop-2-enoate (HDDA), (c) 2-hydroxy-2-methyl-1-phenyl-propane-1-one (Darocur 1173).

\subsection{Sample preparation}

A model system consisting of a photochemically crosslinked polymer network was prepared by UV-vis irradiation of an initial solution of the reactive monomers Abu and HDDA, and Darocur 1173 in the following weight percentages $99.0,0.5$, and $0.5 \mathrm{wt}-\%$, respectively. The solution was stirred mechanically for 24 hours before it was poured into Teflon moulds to obtain discs having a diameter of $3 \mathrm{~cm}$. The irradiation process was carried out under nitrogen atmosphere using UV Philips TL08 lamps exhibiting a wavelength of $\lambda=365 \mathrm{~nm}$ and an intensity $\mathrm{I}_{0}=1.5 \mathrm{~mW} \mathrm{~cm}^{-2}$. The exposure time was fixed at $15 \mathrm{~min}$ to achieve a complete conversion of monomers and the obtained crosslinked polymers were optically transparent.

\subsection{Swelling investigation}

The swelling degree of the obtained crosslinked PABu network samples in each organic 
solvent was measured gravimetrically at a constant temperature of $25^{\circ} \mathrm{C}$. The dried samples were immersed in an appropriate container filled with excess of solvent, and the swelling kinetics was followed every $5 \mathrm{~min}$ for a period of one hour, then every $30 \mathrm{~min}$ for 2 hours, and finally every hour for several days (except during night time), upon reaching equilibrium swelling states. The sample was then removed from the container and weighted after removal of excess solvent on the surface. The swelling degree by weight, denoted $S D W$, can thus be calculated by the following equation:

$$
\operatorname{SDW}(t)=\frac{w(t)-w_{0}}{w_{o}}
$$

where $w_{0}$ represents the weight of the dried sample (initial state), and $w(t)$ stands for the weight of the swollen sample at a given soaking time $t$.

\section{Results and Discussion}

\subsection{Swelling study}

The swelling properties of photochemically crosslinked PABu networks were investigated by isothermal gravimetric sorption measurements. For example, Figure 2 shows representative

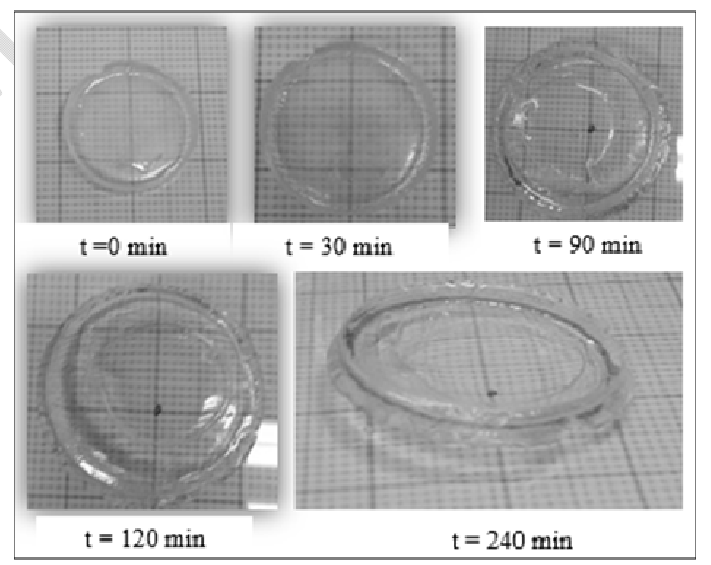

Figure 2: Photographs of chemically crosslinked $\mathrm{PABu}$ network samples at $\mathrm{T}=25^{\circ} \mathrm{C}$ in dried state and as function of soaking time in heptan-1-ol. 
photographs of a disc shaped PAbu sample in dry state and after immersion in excess heptan1-ol for different soaking periods. Relatively slow solvent uptake was observed, and the equilibrium state was reached only after a period of several tenths of hours. The sample swollen in heptan-1-ol was optically transparent and quite larger than the network soaked in methanol.

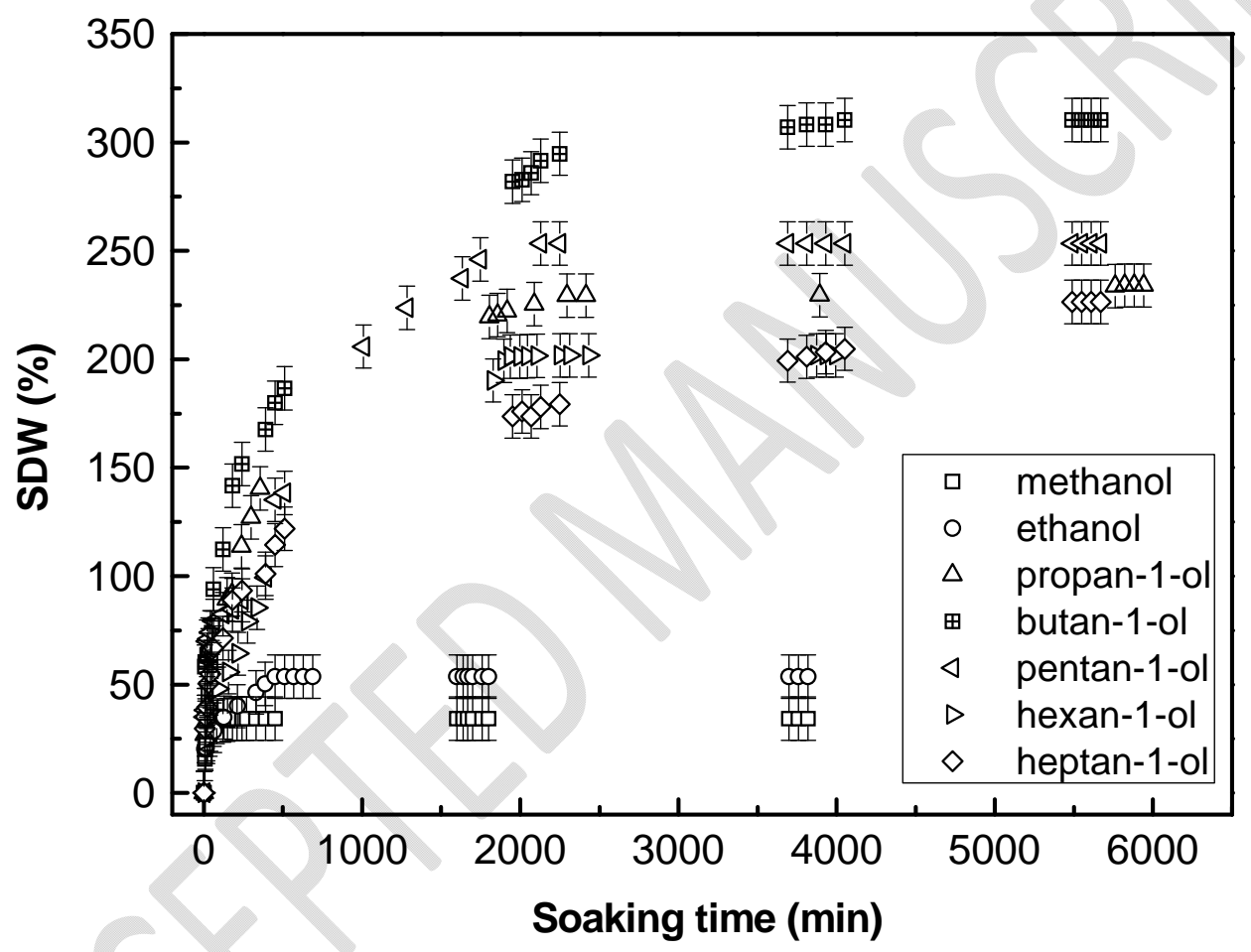

Figure 3: Swelling behavior of chemically crosslinked PABu network samples as function of soaking time for different linear primary alcohols at $\mathrm{T}=25^{\circ} \mathrm{C}$.

Figure 3 represents the solvent uptake in terms of $S D W$ of chemically crosslinked PABu network samples, as function of soaking time in linear primary alcohols, by varying their alkyl chain lengths from methanol to heptan-1-ol. It should be mentioned that increasing the alkyl chain length of the alcohols promotes swelling considerably since at equilibrium 
methanol exhibits $S D W=0.35$ and for heptan-1-ol $S D W=2.26$. Interestingly $S D W$ of butan-1-ol reached 3.25 at equilibrium and further increase of the alkyl chain length leads to a decrease of $S D W$ which becomes then constant. This investigation could not be carried out for heavy alcohols beyond heptan-1-ol since they present a solid state at $25^{\circ} \mathrm{C}$.

\subsection{Swelling data analysis}

The experimental swelling data from Fig. 3 can be described applying a second-order swelling kinetics equation:

$$
\frac{d S D W}{d t}=k\left(S D W_{e}-S D W\right)^{2}
$$

where $S D W_{e}$ represents the swelling degree by weight at equilibrium and $k$ stands for the swelling rate coefficient. Integration of Eq. 2 leads to:

$$
\frac{1}{S D W_{e}-S D W}-\frac{1}{S D W_{e}}=k t
$$

Further linearization gives Eq. 4:

$$
\frac{t}{S D W}=A t+B
$$

The constant $A=1 / S D W_{e}$ represents the normalized inverse equilibrium swelling degree of the sample for a given solvent and $\mathrm{B}=1 /(d S D W / d t)_{0}=1 /\left(k S D W_{e}^{2}\right)$ is the reciprocal of the initial swelling rate of the PABu network. Eq. 4 allows thus to determine $k$ and $S D W_{e}$. Figures 4 a and $\mathbf{4 b}$ show the swelling data from Fig. 3 by applying Eq. $\mathbf{4}$ for methanol, ethanol, propan-1ol, and butan-1-ol, pentan-1-ol, and hexan-1-ol, respectively. Figures $4 \mathbf{a}$ and $\mathbf{4 b}$ reveal that the swelling curves could be fitted by linear regression analysis according to Eq. 4. Initial swelling rates and the values of maximum swelling were calculated from $\mathrm{A}$ and $\mathrm{B}$ coefficients. All corresponding data were gathered in Table S2. It should be mentioned that the correlation coefficient $\left(\mathrm{R}^{2}\right)$ regularly decreases from 1 for methanol to 0.980 for hexan-1ol, by increasing the aliphatic chain length of the primary alcohol. 

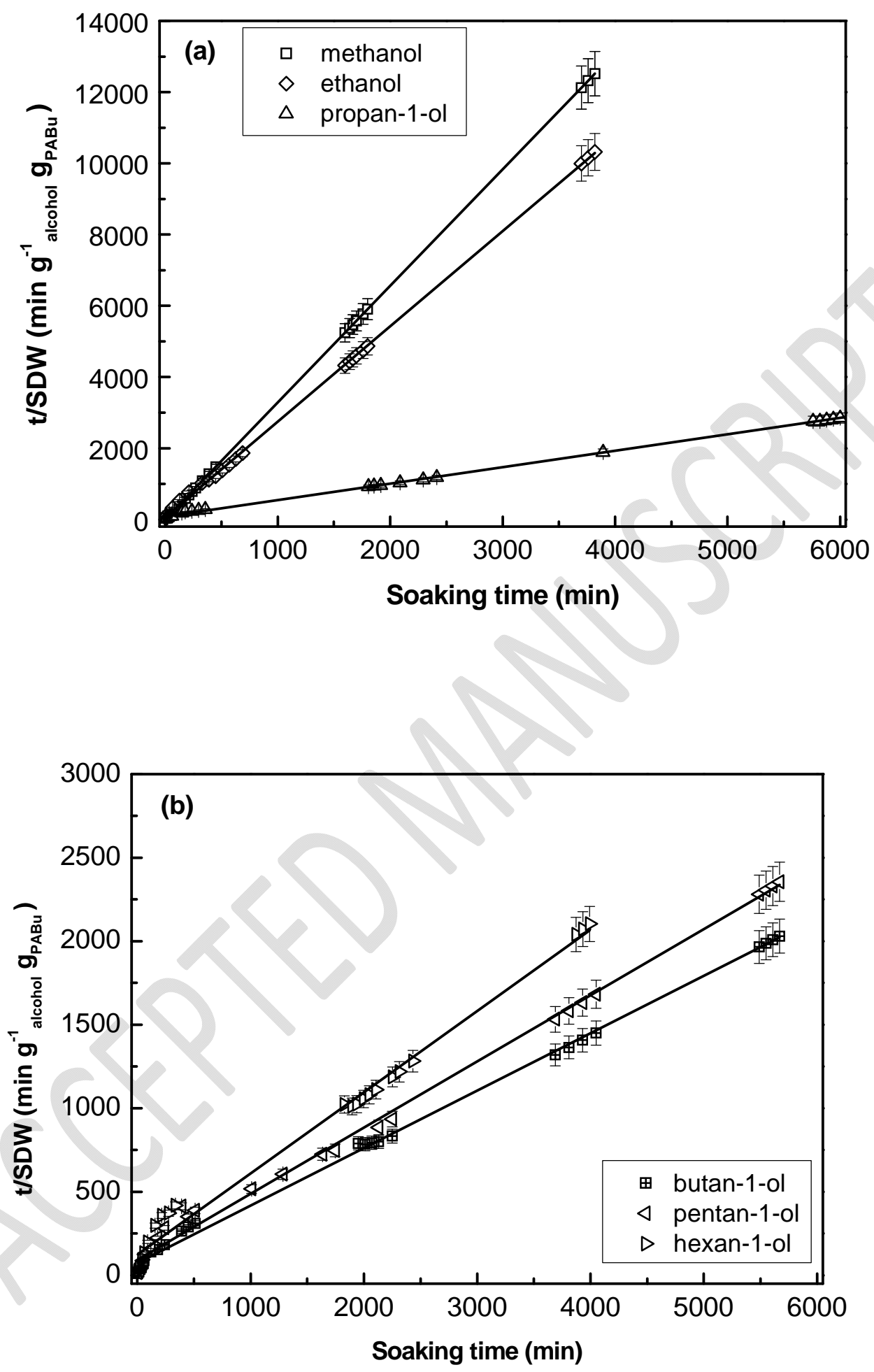

Figure 4: Variation of $t / S D W$ as a function of soaking time according to Eq. 4 for chemically crosslinked PABu networks in the case of a) methanol, ethanol, and propan-1-ol; b) butan-1ol, pentan-1-ol, and hexan-1-ol. 
As a result, heptan-1-ol, which was evaluated as well, was not included here since its corresponding data could not be fitted by Eq. 4. Figure 5 represents $S D W_{e}$ and $k$ values deduced from data of Fig. $\mathbf{4 a}$ and $\mathbf{4 b}$.

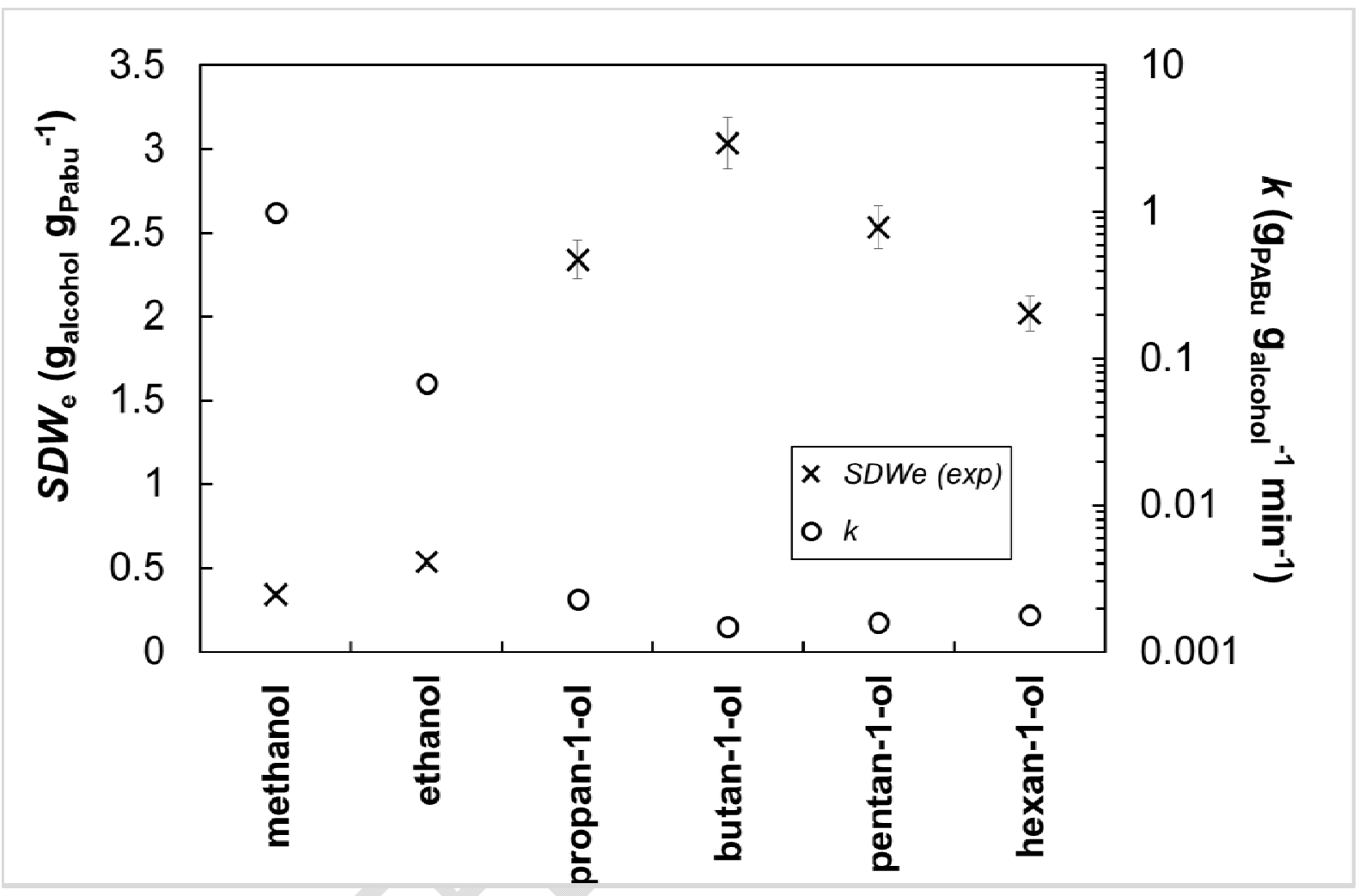

Figure 5: Swelling parameters of chemically crosslinked PAbu networks in linear primary alcohols, from data processing using Eq. 4.

As expected from Fig. 3, $S D W_{e}$ presents an unusual maximum for butan-1-ol. Beyond this confirmation, Fig. 5 also indicates that the rate coefficient of swelling $k$ decreases from methanol to butan-1-ol and remains then constant up to hexan-1-ol, revealing that swelling kinetics become slower for larger alcohols beyond butan-1-ol. One can hence conclude from both data types of Fig. 5 that both methanol and ethanol quickly enter the polymer network 
but poorly constrain the polymer once facing its internal surface. This scheme changes completely when considering propan-1-ol and other larger alcohol molecules.

\subsection{Solubility parameters}

An attempt was made to understand the unusual "butan-1-ol effect" through consideration of solvent and polymer solubility parameters. The solubility parameter established by Hildebrand [37-38] is defined as the square root of the vaporization energy per unit volume of the material under consideration and is given by the $\delta$ symbol. In a binary polymer/solvent system, mixing enthalpy will decrease if the difference between the corresponding solubility parameters becomes small, so that mutual miscibility will be favored. Hildebrand concluded that the quantity $\left(\delta_{\text {Polymer }}-\delta_{\text {Solvent }}\right)^{2}$ governs solubility effects, and should be as small as possible to reach good solubility of a polymer in a solvent. Hansen [33-35] introduced splitting of this "global" parameter into three main components: London dispersion $\delta_{\mathrm{D}}$, Keesom polarity forces $\delta_{\mathrm{P}}$ (between permanent dipoles), and hydrogen bonding forces $\delta_{\mathrm{H}}$. The cohesive energy is then divided into three parts, corresponding to the three types of interaction forces, and the solubility parameter represents the square root of the sum of the squares of $\delta_{\mathrm{D}}$, $\delta_{\mathrm{P}}$ and $\delta_{\mathrm{H}}$. Table S3 gathers the calculated Hansen solubility parameters (HSP) and their components for the primary alcohols and linear PABu.

Fedors model [36] is known as an incremental group contribution method where each of these groups possesses their own properties (molar volume $\left(V_{i}\right)$, molar cohesive energy $\left(e_{i}\right)$, etc.). For the calculation of the solubility parameter, Fedors model assumes additivity of $e_{i}$ and $V_{i}$, separately, and leads to the following relationship:

$$
\delta=\sqrt{\frac{\sum e_{i}}{\sum V_{i}}}
$$


Solubility parameters were calculated using Fedors method and the results are shown in Table S3. It should be pointed out that the calculated $\left(\delta_{\text {Polymer }}-\delta_{\text {Solvent }}\right)^{2}$ parameter decreases regularly with the alkyl chain length of the primary alcohols, i.e. it goes from $116.6 \mathrm{~J} \mathrm{~cm}^{-3}$ for methanol to $2.9 \mathrm{~J} \mathrm{~cm}^{-3}$ for heptan-1-ol (HSP, [33-35]), and from 84.7 to $5.3 \mathrm{~J} \mathrm{~cm}^{-3}$ using Fedors method [36] applied to the solubility parameter of the linear polymer $\left(\delta_{\text {Polymer }}=\right.$ $\delta_{\mathrm{PABu}}^{*}$. According to these calculations, heptan-1-ol would be the best solvent for the considered $\mathrm{PABu}$ polymer, but this is not what experiments are telling us, as it will be seen later.

Gee [39] made the assumption that the solubility parameters of polymer and solvent will not differ very much when polymer-solvent interactions and polymer swelling are maximal. The dependence of the swelling degree at equilibrium on the $\delta_{\text {Solvent }}$ value can thus be expressed by a curve with a maximum at $\delta_{\text {Solvent }}=\delta_{\text {Polymer }}$ coordinate. This approach is considered presently for the cross-linked PABu network. The Swelling Degree by Volume at equilibrium, denoted $S D V_{e}$, is related to $S D W_{e}$ by:

$$
S D V_{e}=1+S D W_{e} \frac{\rho_{P A B u}}{\rho_{\text {solvent }}}
$$

where the solvent density values, $\rho_{\text {solvent }}$, are given in Table $\mathbf{S} 4$ and that of the polymer was taken as $\rho_{P A B u}=1.087 \mathrm{~g} \mathrm{~cm}^{-3}$ [40]. Gee developed the following relationship for the polymer network assuming volume additivity

$$
S D V_{e}=S D V_{e, \max } \exp \left(-\alpha S D V_{e}\left(\delta_{\text {solvent }}-\delta_{P A B u}\right)^{2}\right)
$$

where $S D V_{e, \max }$ stands for $S D V_{e}$ at the maximum of the curve of Fig. 6a, $\alpha$ represents an empirical coefficient, and $\delta_{\mathrm{PABu}}$ denotes the solubility parameter of the elaborated crosslinked PABu polymer. The experimental $S D V_{e}$ data can be rationalized applying Gee's model (Eq. 7a), as well as by the approach of Tager and Kolmakova [41]. The latter can be described by Eq. 7b: 

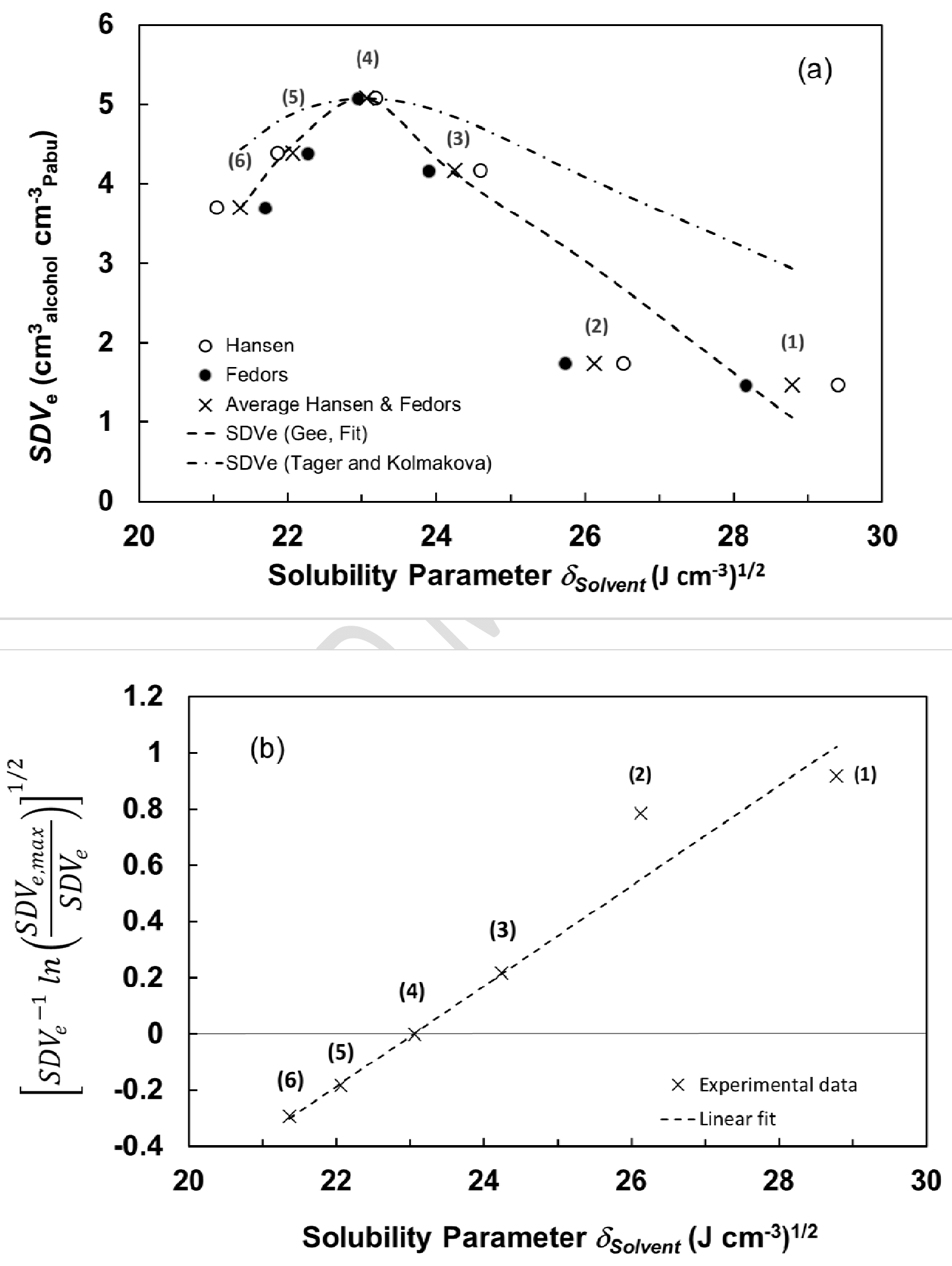


\section{Figure 6:}

a) $S D V_{\mathrm{e}}$ data of the chemically crosslinked $\mathrm{PABu}$ networks from fitting procedures applying models from Gee as well as from Tager and Kolmakova,

b) Plot of $\left[S D V_{e}^{-1} \ln \left(\frac{S D V_{e, \max }}{S D V_{e}}\right)\right]^{1 / 2}$ (Eq. 8) as function of calculated solubility parameters of the primary alcohols according to Gee's model.

1: methanol, 2: ethanol, 3: propan-1-ol, 4: butan-1-ol, 5: pentan-1-ol, 6: hexan-1-ol, 7: heptan1-ol). According to an estimation of $5 \%$ error of the $S D V_{e}$ values, the size of error bars remained smaller than that of the symbols representing the experimental data points.

Figure 6a shows the results of this comparison considering calculated averaged Hansen and Fedors solubility parameters of alcohols. The experimental data from propan-1-ol to hexan-1ol are fairly well fitted by Gee's model whereas only a poor approximation between experimental results and the model of Tager and Kolmakova was observed. Linearization of Eq. 7a yields:

$$
\left[S D V_{e}^{-1} \ln \left(\frac{S D V_{e, \max }}{S D V_{e}}\right)\right]^{1 / 2}=\alpha^{1 / 2}\left(\delta_{\text {solvent }}-\delta_{P A B u}\right)
$$

Plotting of $\left[S D V_{e}^{-1} \ln \left(\frac{S D V_{e, m a x}}{S D V_{e}}\right)\right]^{1 / 2}=f\left(\delta_{\text {solvent }}\right)$, according to Eq. 8 (Fig. 6b), allow to evaluate the linearity of the curve and the corresponding abscissa range. The value of $\delta_{\mathrm{PABu}}$, representing the total solubility parameter of the crosslinked PABu network, was determined as $23.0\left(\mathrm{~J} \mathrm{~cm}^{-3}\right)^{1 / 2}$ at the intercept of the linear fit curve with the abscissa axis, as expected from analysis of Fig. 6a. A value of $0.18 \mathrm{~cm}^{3} \mathrm{~J}^{-1}$ for the $\alpha^{1 / 2}$ coefficient was obtained from linear regression analysis. Graphical evaluation of the dependence of $\left[S D V_{e}^{-1} \ln \left(\frac{S D V_{e, \max }}{S D V_{e}}\right)\right]^{1 / 2}$ on $\delta_{\text {solvent }}$ was carried out for each individual component, i.e. $\delta_{D, \text { solvent }}$ (Fig. S1a), $\delta_{P, \text { solvent }}$ (Fig. S1b), and $\delta_{H, \text { solvent }}$ (Fig. S1c). A quasi-linear trend 
could be observed on each graph for primary alcohols in the range from propan-1-ol to hexan1-ol. The corresponding $\mathrm{x}$-intercepts allowed to deduce the individual components of the crosslinked polymer, i.e. $\delta_{D, P A B u}=16.0\left(\mathrm{~J} \mathrm{~cm}^{-3}\right)^{1 / 2}, \delta_{P, P A B u}=5.7\left(\mathrm{~J} \mathrm{~cm}^{-3}\right)^{1 / 2}$ and $\delta_{H, P A B u}=15.8$ $\left(\mathrm{J} \mathrm{cm}^{-3}\right)^{1 / 2}$ (see also Table S3). Using these data, the total solubility parameter of the crosslinked PABu was recalculated as $\delta_{P A B u}=23.2\left(\mathrm{~J} \mathrm{~cm}^{-3}\right)^{1 / 2}$. The strong increase of $\delta_{P A B u}$ compared to $\delta^{*}{ }_{P A B u}$ mainly comes from the increase of the $H$ component of the crosslinked polymer.

The $\delta_{P A B u}$ value deduced from Fig. 6b significantly deviates from the calculated values from Hansen and Fedors models. Indeed, considering a linear structure of $\mathrm{PABu}$, calculation of HSP gives $\delta^{*}{ }_{P A b u}=18.8\left(\mathrm{~J} \mathrm{~cm}^{-3}\right)^{1 / 2}$ (Table S3), whereas Fedors method yields $\delta^{*}{ }_{P A b u}=19.0(\mathrm{~J}$ $\left.\mathrm{cm}^{-3}\right)^{1 / 2}$ (Table S4).

Charles M. Hansen and coworkers published several papers on measuring the solubility parameters of swollen materials [34,42-43]. Following these reports, the HSP for the crosslinked $\mathrm{PABu}$ were experimentally determined from equilibrium swelling data of a set of 24 organic solvents (including the primary alcohols considered here), covering a wide range of known partial solubility parameters. A computer program (MATLAB software) allowed calculating partial solubility parameters of the crosslinked PABu in the three-dimensional space, applying an optimization procedure based on the Nelder-Mead algorithm [44-46]. The program results in the formation of a solubility sphere which contains a maximum of good swelling solvents $i(s(i)=1)(s=$ score $)$ and a minimum of partially swelling solvents $(s(i)=0)$ (see Table S1 for details). The centre coordinates of this sphere represent three-dimensional HSP of the crosslinked PABu (dispersion $\left(\delta_{d p}\right)$, polar $\left(\delta_{p p}\right)$ and hydrogen-bond $\left(\delta_{h p}\right)$ forces); its radius $R_{0}$ was minimized using the "size factor" proposed by Vebber et al. [47]. These four parameters were the targets of the optimization procedure. For each solvent $i$, whose HSP parameters are $\quad \delta_{d}(i), \quad \delta_{p}(i)$ and $\quad \delta_{h}(i), \quad$ the parameter 
$R_{a}(i)=\sqrt{\left(\delta_{d p}-\delta_{d}(i)\right)^{2}+\left(\delta_{p p}-\delta_{p}(i)\right)^{2}+\left(\delta_{h p}-\delta_{h}(i)\right)^{2}}$ was compared to $R_{0}$, and a parameter $A(i)$ was defined: if $R_{a}(i)<R_{0}$ and $s(i)=1$ or if $R_{a}(i)>R_{0}$ and $s(i)=0$, then $A(i)=1$, else $A(i)=e^{-\left|R_{a}(i)-R_{0}\right|}$. The objective of the optimization procedure was to minimize the error $r=1-\left(\frac{\prod A(i)}{R_{0}}\right)^{1 / n}=1-\frac{A}{R_{0}^{1 / n}}$, where $n$ represents the number of solvents. The following results were obtained from the optimization procedure : $\delta_{P A B u}=23.07$ $\left(\mathrm{J} \mathrm{cm}^{-3}\right)^{1 / 2}, \delta_{\mathrm{d}}=20.12\left(\mathrm{~J} \mathrm{~cm}^{-3}\right)^{1 / 2}, \delta_{\mathrm{p}}=9.29\left(\mathrm{~J} \mathrm{~cm}^{-3}\right)^{1 / 2}, \delta_{\mathrm{h}}=6.41\left(\mathrm{~J} \mathrm{~cm}^{-3}\right)^{1 / 2}, R_{0}=13.0, A=0.886$. Interestingly, the value of the total solubility parameter of the crosslinked PABu determined by using swelling data from 24 organic solvents was found to be close to that obtained for the primary alcohols applying Eq. 8.

An attempt was made to correlate the swelling data with the three individual component differences of solubility parameters. Fig. S2 presents the percent swelling results $\left(S D W_{e}\right)$ as function of the Hansen RED (Relative Energy Difference) numbers, which are given by $\mathrm{RED}=R_{\mathrm{a}}(\mathrm{i}) / R_{\mathrm{o}}$ (see Table S1). In this approach, RED numbers were calculated for each pair of solvent and crosslinked PABu. A quite good correlation was found between swelling data and RED numbers. As expected, when $R_{\mathrm{a}}$ becomes smaller than the interaction radius $R_{0}$, the swelling ratio increases. On the other hand, when $R_{\mathrm{a}}$ exceeds $R_{0}$, the swelling ratio decreases. Fig. S2 shows that solvents exhibiting RED numbers roughly below 1.1 present high degrees of swelling (classified as good swelling solvents), whereas solvents with RED numbers roughly above 1.1 give low degrees of swelling (classified as partially swelling solvents).

Fig. S2 also reveals that the good correlation between swelling data and RED numbers remains also valid for the primary alcohols, which are presented in red colour in this figure. Especially 1-butan-ol fits well within the range of data points of the surrounding other organic solvents. 
Clearly the above discussed relationships based on the polymer-solvent solubility parameters cannot explain the unexpected swelling of butan-1-ol. Gee pointed out that departures from conformity are attributable to imperfection of the theory of regular solutions [39], which does not take into account specific interactions.

\subsection{Alcohol-polymer interaction modeling}

In this section, modeling of polymer-alcohol interactions was performed in an attempt to better understand the experimental results given in Fig. 3. With this aim, a commercial molecular modeling software (Spartan '16, Wavefunction Inc.) was implemented to illustrate the presence of interactions between linear primary alcohols (denoted, for modeling purpose, $A_{n}, n=1 \ldots 7 ;$ starting from methanol $(\mathrm{n}=1)$ to heptan-1-ol $\left.(\mathrm{n}=7)\right)$ and molecular arrangement simulating the crosslinked $\mathrm{PABu}$ network. To setup the solver, the equilibrium geometry option was considered with use of density function $\left(\omega \mathrm{D} 97 \mathrm{X}-\mathrm{D} / 6-31 \mathrm{G}^{*}\right)$ which enable energy minimizing of large molecules. The molecules were assumed to be isolated from each other in order to focus on specific interactions between polymer and alcohols. No conformer distribution was used despite the fact that it may have improved the results, but it reveals to be too much time consuming. The energy minimization procedure was hence based on electrostatic repulsion/attraction forces, deformation of transient bonds, and return to equilibrium of the system. The crosslinked PABu-like structure was constructed on the basis of 2 linear chains of 8 Abu monomers crosslinked through 2 HDDA bridges at $1 / 4$ th and $3 / 4$ th of their respective lengths. A schematic illustration of the crosslinked PABu structure is given in Fig 7. Two independent but similar polymer blocs like that shown in Fig. 7 were considered in order to account for their mutual influence resulting from the interaction with alcohols. 


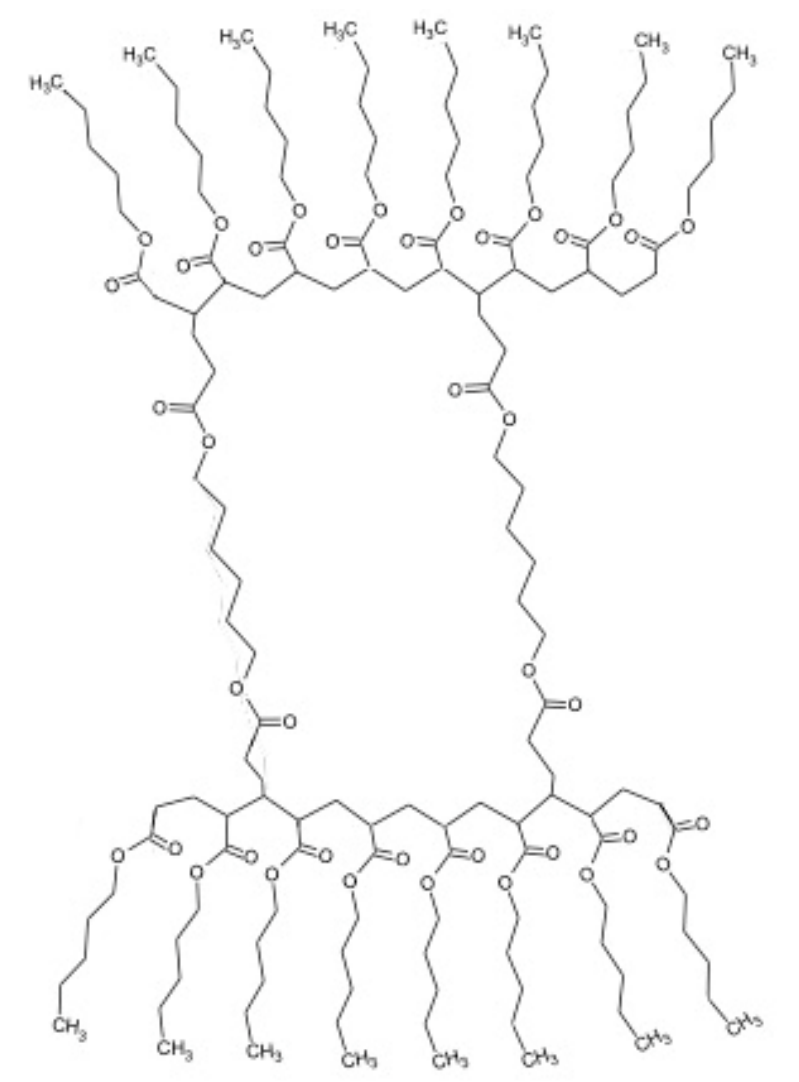

7

Figure 7: Schematic illustration of the polymer-like structure used to simulate the chemically crosslinked PABu network, before performing energy optimization procedure.

The shape shown in Fig. 7 was of course modified by the energy minimization due to the rearrangements. The result is not shown here since the $3 \mathrm{D}$ shape of the two optimized blocs does not provide useful information. Data related to the value of the minimized energy of the considered molecular arrangement $\left(E(\right.$ Polym $\left.)=446.5 \mathrm{~kJ} \mathrm{~mol}^{-1}\right)$ were obtained as main output from this process. In a second step, the individual minimum energy was calculated for each alcohol molecule (denoted $\varepsilon\left(A_{i}\right), i=1 \ldots 7$ ), but also that of a set of ten identical alcohol molecules (denoted $E\left(10 A_{i}\right), i=1 \ldots 7$ ) in order to get the average energy per alcohol molecule related to their mutual interaction (mainly "hydrogen bond" (HB) interactions (H...HO-C-, 
water-like)) and dipole-dipole (van der Waals (vdW)) interactions), denoted $\varepsilon_{\text {int }}\left(A_{i}-A_{i}\right)$, $i=1 \ldots 7$. The latter can be expressed by the following equation:

$$
\varepsilon_{\text {int }}\left(A_{i}-A_{i}\right)=\left(E\left(10 A_{i}\right)-10 . \varepsilon\left(A_{i}\right)\right) .\left(10-N\left(\text { isol. } A_{i}\right)\right) / 10 \quad i=1 \ldots 7
$$

where $N\left(\right.$ isol. $\left.A_{i}\right)$ represents the number of isolated (HB interaction-free) alcohol molecules. The "HB interaction-free" state is related to the background energy of the alcohol outside the polymer region, and does not contribute to the interaction term. Eq. 9 takes into account the molecules effectively participating to HB interactions. The obtained energy values were gathered in Table S5. The number of $A_{i}-A_{i}$ interactions $\left(N\left(A_{i}-A_{i}\right)\right)$ taking place in the pure alcohol system and deduced from resulting 3D image analysis were determined, as well as those of the interaction-free molecules $\left(N\left(\right.\right.$ isol. $\left.\left.A_{i}\right)\right)$. As a result, the interaction energy term of the pure solvent system $E_{\text {int }}\left(A_{i}-A_{i}\right)_{s}$ exhibits a maximum like $N\left(\right.$ isol. $\left.A_{i}\right)$ while $N\left(A_{i}-A_{i}\right)$ shows a minimum for butan-1-ol case. This statement ascribes for the balance between the attractive forces due to HB interactions which are very strong for methanol and ethanol, and mutual attraction via vdW interactions playing a main role for hexan-1-ol and heptan-1-ol molecules. Compared to the other alcohols considered here, butan-1-ol seems to gather overlapping of both effects, leading to the smallest attraction and subsequently to the highest number of isolated molecules. Note that contributions from $\mathrm{HB}$ and vdW interactions in the $E_{\text {int }}\left(A_{i}-A_{i}\right)_{s}$ term were not discriminated. Thereafter, the crosslinked PABu structure was put together with the set of ten identical alcohol molecules (only one polymer bloc is in fact "mixed" with the alcohol molecules), and energy minimization was achieved again. The resulting energy term was designated $E\left(\right.$ Polym $\left.+10 A_{i}\right), i=1 \ldots 7$, and the corresponding values are given in Table S6. It is then possible to provide the energy of the overall interactions (denoted $E_{\text {int }}(\text { Total })_{s-p}\left(s-p\right.$ : solvent-polymer system), as the summation of the $A_{i}-A_{i}$ component but also that of $A_{i}-$ Polym) by the following relation:

$$
E_{\text {int }}(\text { Total })_{s-p}=E\left(\text { Polym }+10 A_{i}\right)-E(\text { Polym })-10 . \varepsilon\left(A_{i}\right) \quad i=1 \ldots 7
$$


This set of calculated energy values must be completed by the information about nature and number of hydrogen bonds by making a difference between $-\mathrm{H}$...HO-C- contributions, related to $A_{i}-A_{i}$ interactions, $\left(N\left(A_{i}-A_{i}, H B\right)_{s-p}\right)$, and both $\mathrm{H} \ldots \mathrm{O}=\mathrm{C}<($ ketone groups $)$ and $\mathrm{H} . . \mathrm{O}<$ (ether groups) contributions, which correspond to $A_{i}$-Polym interactions $\left(N\left(A_{i}-\right.\right.$ Polym)). The corresponding data are given in Table S6. The values of $E_{\text {int }}$ (Total) $_{s-p}$ obtained from Eq. 10 and listed for each alcohol in Table $\mathbf{S 6}$ can then be exploited to share the $A_{i}-A_{i}$ from $A_{i}$-Polym contributions. Despite both $A_{i}$-Polym components could be evidenced by visual analysis of the $3 \mathrm{D}$ image, it was not possible to distinguish them numerically in the energy term. The analysis of nature and numbers of interactions shows different features:

a) The overall number of HB interactions gradually decreases from 10 to 6 while increasing $i$. This implies that by increasing the alkyl chain length of the alcohols, their individual motion in the free volume will become easier. This confirms, to some extent, at least qualitatively the conclusions drawn from Table S2 and from Table S6, i.e. methanol and ethanol present the highest $k$ values and show the largest rate of interactions with the crosslinked PABu network with respect to the other alcohols, respectively.

b) Once again, the $A_{i}-A_{i} \mathrm{HB}$ interactions are low for butan-1-ol but the dependence of $N\left(A_{i}\right.$ $\left.A_{i}, H B\right)_{s-p}$ on $A_{i}$ seems to be more complex and their corresponding values are lower, as expected, than for the pure solvent system. There is of course competition with the $A_{i}$-Polym interactions. Nevertheless, $A_{i}-A_{i} \mathrm{HB}$ interactions remains dominant compared to those from $A_{i}$-Polym, and represent more than half of the overall interactions.

c) Solvent-polymer interactions are dominated by $\mathrm{H} \ldots \mathrm{O}=\mathrm{C}<$ forces. The $\mathrm{H} \ldots \mathrm{O}<$ component occurs only for small alcohols and vanishes beyond propan-1-ol. This trend may come from sterical effects, due to increased mutual obstruction of the larger alcohols in the movement for reaching the ether groups with respect to the dangling ketone groups. 
d) No isolated alcohol molecule could be evidenced by visual analysis of the 3D images. This implies that the polymer network retains each molecule through these new interactions.

Figure 8 presents the extreme cases for illustration of the overall behavior of the alcohol molecule in presence of the polymer network: methanol (Fig. 8a), butan-1-ol (Fig. 8b) and heptan-1-ol (Fig. 8c). The images were obtained with the help of ACD/ChemSketch and ACD/3D Viewer softwares 20152.5 (freewares). For simplification purpose, only a small fraction of the polymer was sketched and faces the ten identical alcohol molecules. These illustrations should be seen as pictures of typical situations drawn from molecular simulation and as graphical interpretations of the three situations described by the values of $N\left(A_{i}-\right.$ $\left.A_{i}, H B\right)_{s-p}$ and of $N\left(A_{i}-\right.$ Polym $)$ for $(\mathrm{H} \ldots \mathrm{O}=\mathrm{C}<)$ and $(\mathrm{H} \ldots \mathrm{O}<)$ bonds from Table S6.

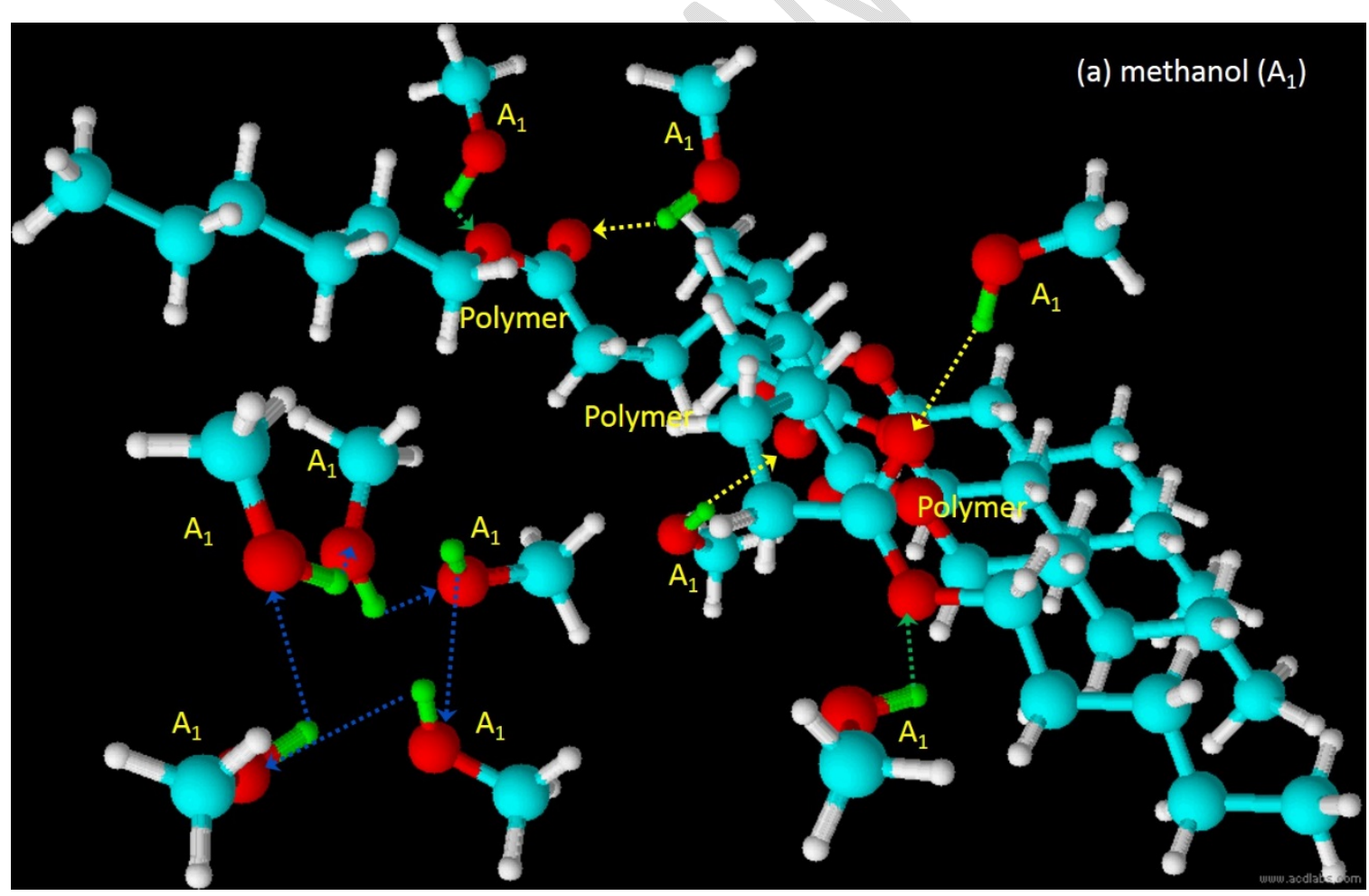




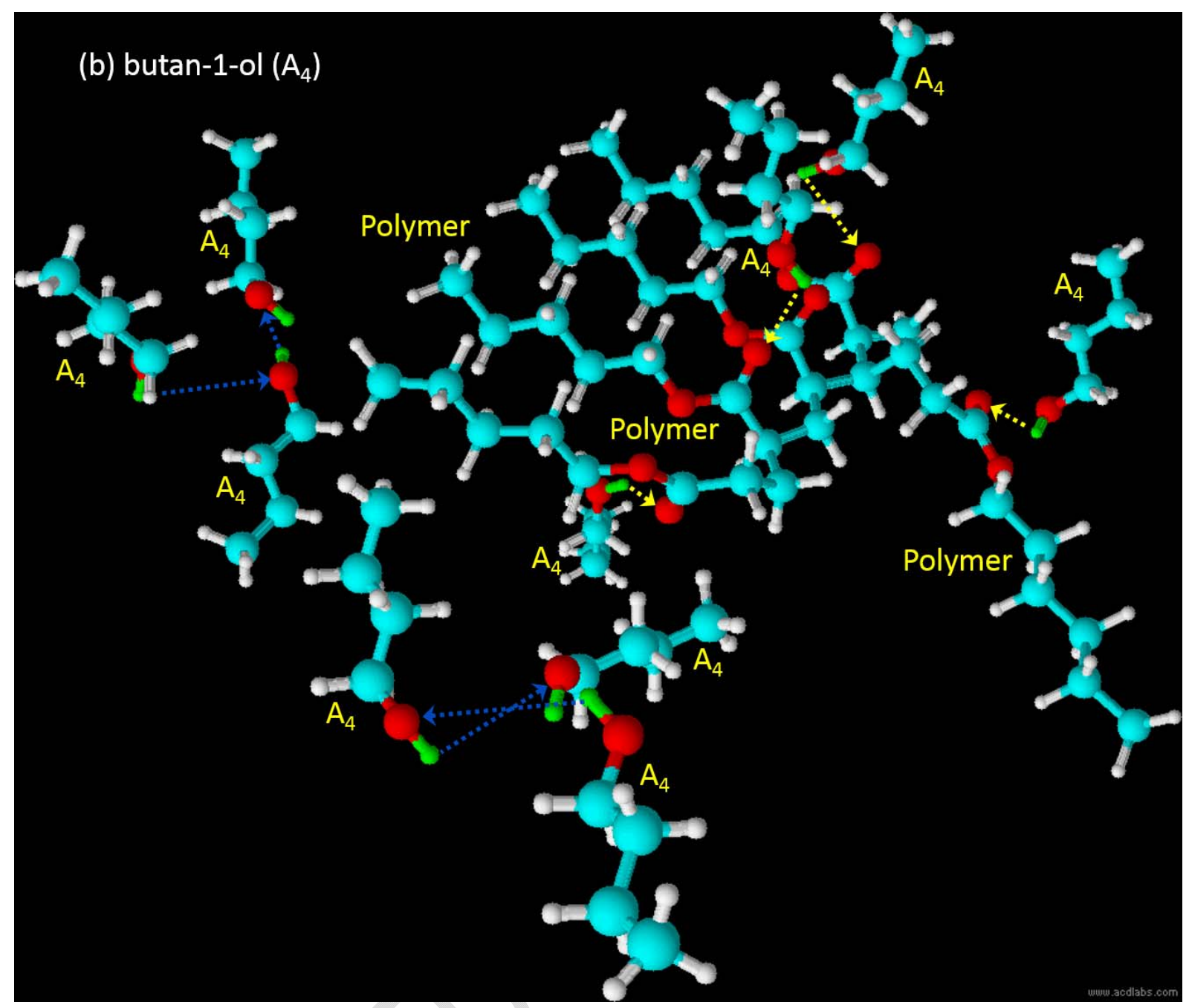




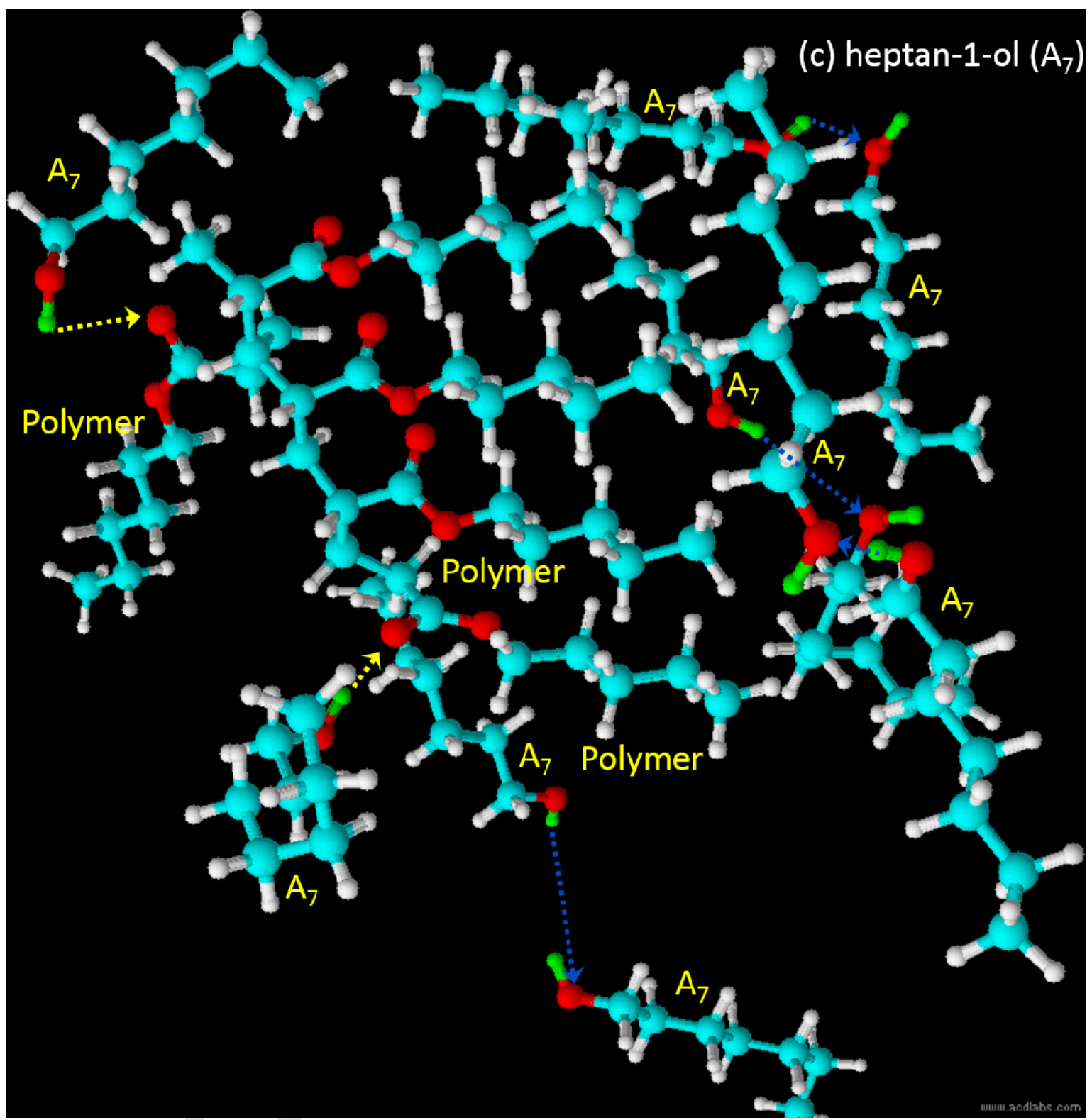

Figure 8: Typical situations issued from molecular simulations and related to the values of $N\left(A_{i}-A_{i}, H B\right)_{s-p}$ (intermolecular HB bonds, blue arrows) and of $N\left(A_{i}-\right.$ Polym $)$ for $(\mathrm{H} \ldots \mathrm{O}=\mathrm{C}<)$ (yellow arrows) and (H... $<$ ) (green arrows) bonds for: (a) methanol, (b) butan-1-ol and (c) heptan-1-ol (see Table S6).

In the case of methanol, the small side of the molecule supports its penetration into the polymer to interact with it through both bond types $(3 \mathrm{H} \ldots \mathrm{O}=\mathrm{C}<$ and $2 \mathrm{H} \ldots \mathrm{O}<$ bonds) but strong mutual interactions are also favored thanks to the small carbonaceous chain length and 
their prominent polar sites. The intermediate size of butan-1-ol also favors penetration into the polymer bulk but only $\mathrm{H} . . . \mathrm{O}=\mathrm{C}<$ bonds (four) are seen since dangling ketone groups remain still accessible to this molecule. For the largest considered alcohol, e.g. heptan-1-ol, the size effect, so the movement embarrassment, becomes prominent and HB bonding gets more difficult. Few molecules (two) succeed to reach the ketone groups inside the polymer and intermolecular interactions are dominating.

Knowledge of the weights of the different interaction contributions allows calculation of the energy terms $E_{\text {int }}\left(A_{i}-A_{i}\right)_{s-p}$ and $E_{\text {int }}\left(A_{i}\right.$-Polym), namely. This can be achieved by considering the following equations:

$$
\begin{aligned}
& E_{\text {int }}\left(A_{i}-A_{i}\right)_{s-p}=\left(10-N\left(A_{i}-\text { Polym }\right)\right) / 10 . E_{\text {int }}\left(A_{i}-A_{i}\right)_{s} i=1 \ldots 7 \\
& E_{\text {int }}\left(A_{i}-\text { Polym }\right)=E_{\text {int }}(\text { Total })_{s-p}-E_{\text {int }}\left(A_{i}-A_{i},\right)_{s-p} \quad i=1 \ldots 7
\end{aligned}
$$

The calculated values of $E_{\text {int }}\left(A_{i}-A_{i}\right)_{s-p}$ and $E_{\text {int }}\left(A_{i}-\right.$ Polym $)$ given in Table $\mathbf{S 6}$ are presented in Fig. 9. The data on the graphs were normalized to the butan-1-ol-related values for further analysis. The main features of the results can be summarized as:

a) $\quad E_{\text {int }}\left(A_{i}-A_{i}\right)_{s-p}$ values are quite stable up to propan-1-ol. The butan-1-ol $(i=4)$ situation depicts some change in the $A_{i}-A_{i}$ interactions configuration before roughly stabilizing at higher values. This could be explained by the influence of the vanishing of both $\mathrm{H} \ldots \mathrm{O}=\mathrm{C}<$ and $\mathrm{H} \ldots \mathrm{O}<$ interaction types, which may contribute to diminish the $A_{i}-A_{i}$ interaction, beyond the butan-1-ol case.

b) The evolution of $E_{\text {int }}\left(A_{i}\right.$-Polym) with $A_{i}$ makes evidence of a maximum of the interactions of alcohol with the crosslinked $\mathrm{PABu}$ simulated network, which is centered around butan-1-ol, where a balance was found between pure $\mathrm{HB} A_{i}-A_{i}$ and $\mathrm{O}=\mathrm{C}<$ interactions. This could come from some resonance of a size effect between the alkyl chains lengths of both $\mathrm{ABu}$ and butan-1-ol patterns. Note that the abscissa position of this maximum coincides with that shown of the experimental SDW data at equilibrium, e.g. $S D W_{e}$ (Fig. 5). 


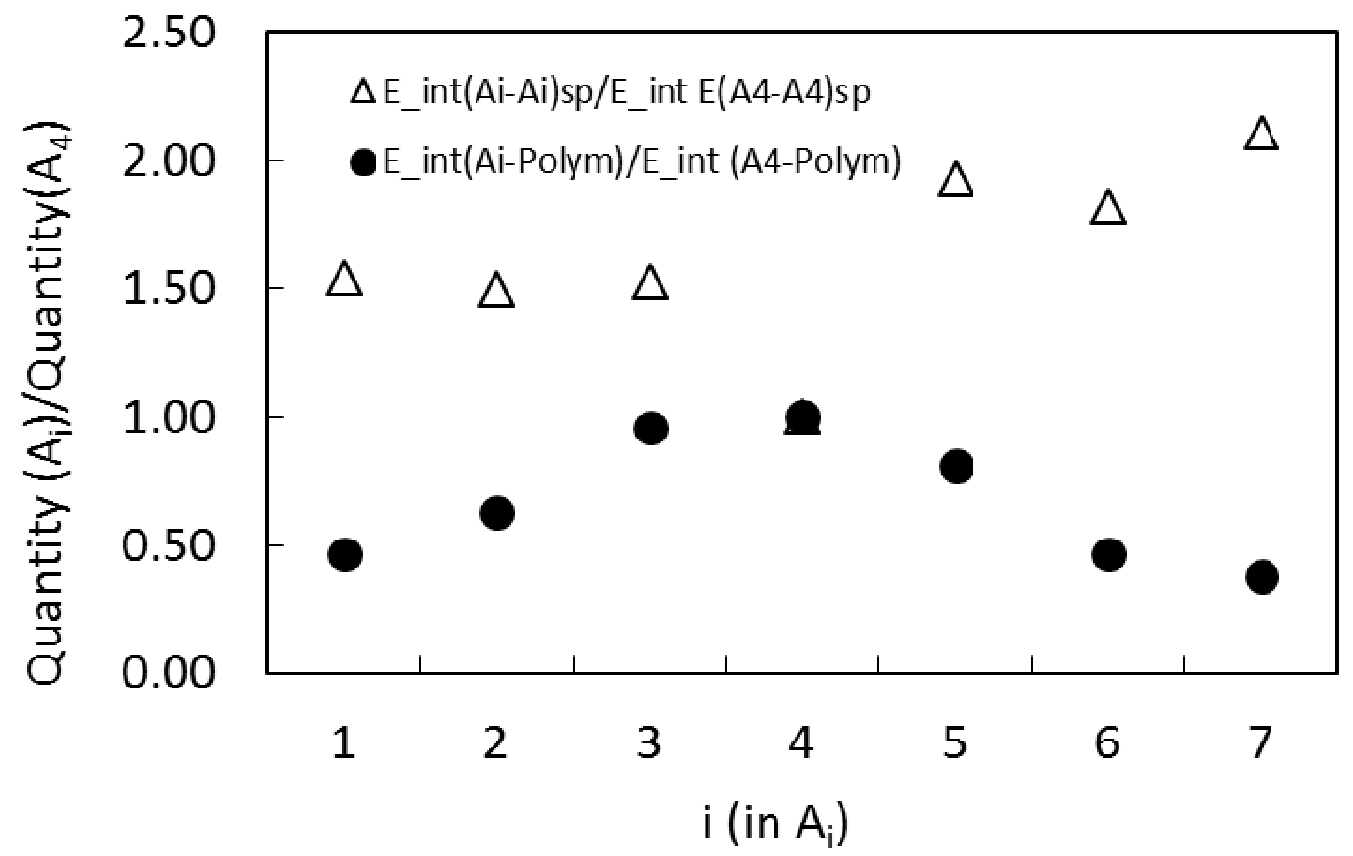

Figure 9: Dependence of $E_{\text {int }}\left(A_{i}-A_{i}\right)_{s-p}$ and $E_{\text {int }}\left(A_{i}-\right.$ Polym $)$ energies vs $i$ in $A_{i}$. All data were normalized to the values related to butan-1-ol.

Figure 10 shows a graph of the variations of $S D W_{e}$ vs $i$ in $A_{i} . S D W_{e}$ data were taken from Fig. 3 in order to include the heptan-1-ol case. These experimental data follow the same general tendency compared to the normalized interaction energy $E_{\text {int }}\left(A_{i}-\right.$ Polym) shown in Fig. 9, i.e. the existence of some correlation between swelling data and $A_{i}$-Polym interactions could be suggested and discussed. This statement concerning the $E_{\text {int }}\left(A_{i}-\right.$ Polym $)$ term could be interpreted as the result of the affinity of the internal surface of the polymer with respect to the considered solvent, mainly governed by HB interactions. The special affinity with butan1-ol was already mentioned. But this calculated energy term does not ascribe completely for the two small alcohols, methanol and ethanol, since their energy values are larger than expected with regard to the normalized $S D_{e}$ values. Of course, there is no immediate relation between swelling and the interaction energy $E_{\text {int }}\left(A_{i}-\right.$ Polym). Some correction should be 
applied to account for contribution to repulsion forces between the polymer chains and the solvent. This can achieved by considering the molar mass of the alcohol, $M$, which is related to the typical size, but mostly to that of the alkyl chain linked to the alcohol group of the solvent. Once the interaction of the solvent has taken place at the interface of the swollen polymer network through $\mathrm{HB}$, the electron pairs of the alkyl groups present both in the polymer and the solvent contribute to short-distance mutual repulsion forces.

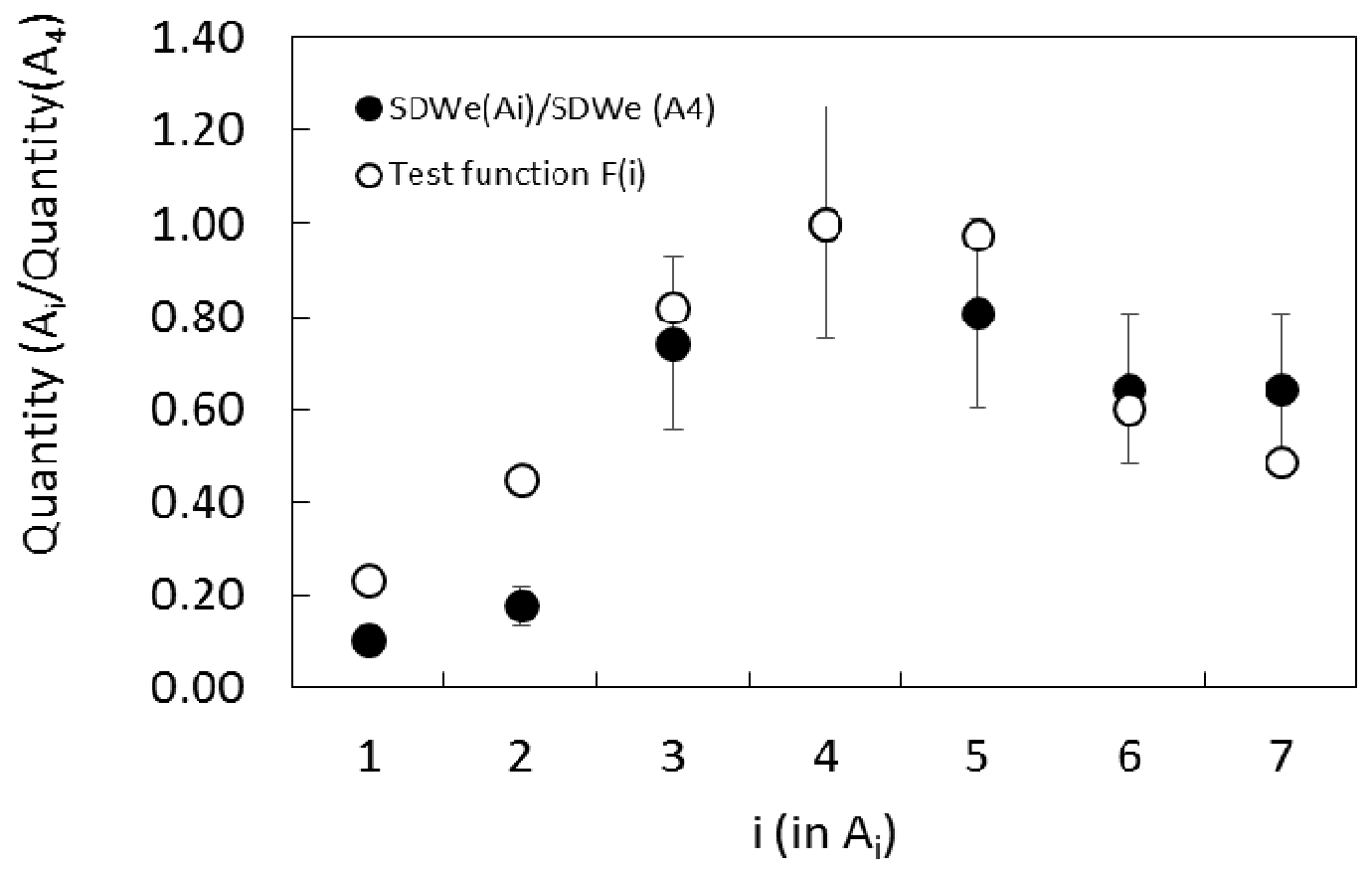

Figure. 10: Dependence of $S D W_{e}\left(A_{i}\right)$ and $F(i)$ (Eq. 13) vs $\mathrm{i}$ in $\mathrm{A}_{\mathrm{i}}$. All data were normalized to the values related to butan-1-ol $(A 4)$. Error bars are related to $S D W_{\mathrm{e}}$.

This effect gets larger and induces more polymer chain deformation as the alkyl chains has more carbons, so as $M$ increases. The simultaneous but opposed contributions of $E_{\text {int }}\left(A_{i}-\right.$ 
Polym) and $M$ can be ascribed by considering their product through an effective function $F(i)$, normalized to value related to butan-1-ol case, defined as follows:

$$
F(i)=E_{\text {int }}\left(A_{i}-\text { Polym }\right) / E_{\text {int }}\left(A_{4} \text {-Polym). } M\left(A_{i}\right) / M\left(A_{4}\right) \quad i=1 \ldots 7\right.
$$

The resulting values of $F(i)$ are given in Fig. 10 for the purpose of comparison with the data relative to mass uptake resulting from experiment. Interestingly a fairly good agreement was observed between the outcome of the theoretical but simple approach (effective function) and the experimental swelling data. Of course, this does not demonstrate formally an univocal relation of $S D W_{e}$ and $F(i)$, but the agreement is sufficiently good to indicate a strong correlation between both quantities. Figure 10 illustrates the transition from $E_{\text {int }}\left(A_{i}-\right.$ Polym $)(i)$ (Fig. 8) to $F(i)$ data. While the matching of experimental data and $F(i)$ shown by Fig. 10 is not perfect, it can be noticed that the $M\left(A_{i}\right)$ term weakens significantly the influence of the $E_{\text {int }}\left(A_{i}-\right.$ Polym) $(i)$ term in $F(i)$ in the range methanol - propan-1-ol. The free volume filled by the alcohol induces less mechanical constraints on the polymer chains due to the small size of their alkyl part and the strong mutual interactions of these latter alcohols. Since their collective movement relative to the polymer is quite fluid, these small alcohol molecules permanently adapt their position to the available volume. Beyond butan-1-ol, the large size of the alcohols leads to less flexibility of fluid volume and improve the mechanical stress induced by repulsive force (electrostatic repulsion, typically) on the polymer chains. This effect, increasing with $M$, compensates the drop of the $E_{\text {int }}\left(A_{i}-P\right.$ olym $)(i>4)$ term which is due to the decrease of the interfacial HB attractions. Many reports exist in literature dealing with polymer simulation but a few of them are related with their swelling behavior on the basis of molecular dynamics simulation [48-51]. Polymer mobility is generally described by Langevin dynamics simulation [48], in which the solvent is considered as a continuum with tunable solvent quality (partially or good swelling properties), governed by free energy parameter. Typical response of a polymer in swelling-collapse cycles is obtained through Flory-Huggins 
(FH) theory and its variants [49]. Most of these models apply on statistical physics to account for chain length-dependent behavior of a single polymer molecule.

Other researchers also worked on prediction of organic solvent permeability through polymer membranes and highlighted its strong dependence on solvent viscosity, pore size and polymer-solvent interaction [50-51]. A main feature of these reports is the strong effort made on polymer membrane construction. They hence computationally monitor swelling and the related pore size. Liu et al. [51] stressed the difficulty to reproduce the subsequent pore size change of the polymer exposed to the considered solvents (methanol, ethanol, acetonitrile and acetone), despite a good trend prediction. They also mentioned, as expected, the main role of solvent-polymer interactions.

\section{Conclusions}

In this study, the swelling properties of a chemically crosslinked PABu network were investigated at room temperature as function of soaking time. A series of seven linear primary alcohols, from methanol to heptan-1-ol, were considered as solvents. The swelling data of these systems were successfully described by second-order kinetics with exception of heptan1-ol. In particular, it has been noticed that swelling degree at equilibrium was strongly influenced, but not linearly, by the length of the alkyl chain of the primary alcohols, since it increases from methanol to butan-1-ol reaching a maximum and then decreases slightly. An attempt was made to explain this unusual "butan-1-ol effect" by discussing solubility parameters using methods developed by Hansen, Fedors, and Gee. Finally, a commercial molecular dynamics software was used to investigate the nature of the interactions of each alcohol with a polymer-like structure simulating the chemically crosslinked PABu network. The study enabled to describe theoretically the experimental swelling data through the 
definition of a function involving the product of the calculated energy of alcohol-polymer interaction and the molar volume.

\section{Acknowledgements}

The authors would like to acknowledge the company Wavefunction, Inc giving us the possibility to evaluate the potential of their software Spartan '16 within the context of this work.

This report has been accomplished in the framework of an international research program. The authors gratefully acknowledge the support of the Algerian Ministry of Higher Education and Scientific Research, the Universities of Béchar and Tlemcen in Algeria, the CNRS, and the University of Lille - Sciences and Technologies/France.

\section{Appendix A. Supplementary material}

Supplementary data associated with this article can be found in the online version at doi:....

\section{Data availability}

The raw/processed data required to reproduce these findings cannot be shared at this time as the data also forms part of an ongoing study.

\section{References}

[1] McKenna GB. Soft matter: rubber and networks. In: Reports on Progress in Physics. 2018;81:Number 6. Bristol: IOP Publishing; 2018.

[2] Nayak AK, Das B. Characterization, Properties and Biomedical Applications. In: Polymeric Gels 1: Introduction to polymeric gels. Cambridge: Kunal Pal and Indranil Banerjee, Woodhead Publishing Series in Biomaterials (Elsevier); 2018. p. 3-27. 
[3] Polymer Gels and Networks. New York: Yoshihito Osada and Alexei Khokhlov, Marcel Dekker; 2001.

[4] Te Nijenhuis K, Thermoreversible networks, viscoelastic properties and structure of gels. Adv Polym Sci 1997;130:1-252.

[5] Erman B, Mark JE. Structure and properties of rubber-like networks. New York: Oxford University Press; 1997.

[6] Dusek K, Responsive gels: volume transitions I and II. Adv Polym Sci 1993;109-110.

[7] Villegas GME, Morselli GR, González-Pérez G, Lugão AB. Enhancement swelling properties of PVGA hydrogel by alternative radiation crosslinking route. Rad Phys Chem 2018. In press.

[8] Maolin Z, Jun L, Min Y, Hongfei H. The swelling behavior of radiation prepared semiinterpenetrating polymer networks composed of polyNIPAAm and hydrophilic polymers. Rad Phys Chem 2000;58:397-400.

[9] Alessi S, Toscano A, Pitarresi G, Dispenza C, Spadaro G. Water diffusion and swelling stresses in ionizing radiation cured epoxy matrices. Polym Degrad Stab 2017;144:137-145.

[10] Khoushabi A, Schmocker A, Pioletti DP, Moser C, Bourban PE. Photo-polymerization, swelling and mechanical properties of cellulose fibre reinforced poly(ethylene glycol) hydrogels. Compos Sci Technol 2015;119:93-99.

[11] Zhang Y, Zhan F, Shi W. Photopolymerization behavior and properties of highly branched poly(thioether-urethane) acrylates used for UV-curing coatings. Prog Org Coat 2011;71:399-405.

[12] Nguyen KT, West JL. Photopolymerizable hydrogels for tissue engineering applications. Biomaterials 2002;23:4307-4314.

[13] Alaba PA, Oladoja NA, Sani YM, Ayodele OB, Mohd W, Daud W. Insight into wastewater decontamination using polymeric adsorbents. J Environ Chem Eng 2018;6:1651- 
[14] Shan D, Gerhard E, Zhang C, Tierney JW, Yang J. Polymeric biomaterials for biophotonic applications. Bioactive Materials 2018;3:434-445.

[15] Oliveira J, Correia V, Castro H, Martins P, Lanceros-Mendez S. Polymer-based smart materials by printing technologies: Improving application and integration. Additive Manufacturing 2018;21:269-283.

[16] Wei C, Huang Y, Liao Q, Fu Q, Sun Y. The kinetics of the polyacrylic superabsorbent polymers swelling in microalgae suspension to concentrate cells density. Bioresour Technol 2018;249:713-719.

[17] Zhang SX, Jiang R, Chai XS, Dai Y. Determination of the swelling behavior of superabsorbent polymers by a tracer-assisted on-line spectroscopic measurement. Polym Test 2017;62:110-114.

[18] Liu Y, Zhang H, Zhang J, Zheng Y. Constitutive modeling for polymer hydrogels: A new perspective and applications to anisotropic hydrogels in free swelling. Eur J Mech A-Solid 2015;54:171-186.

[19] Koetting MC, Peters JT, Steichen SD, Peppas NA. Stimulus-responsive hydrogels: Theory, modern advances, and applications. Mater Sci Eng R Rep 2015;93:1-49.

[20] Kularatne RS, Kim H, Boothby JM, Ware, TH. Liquid crystal elastomer actuators: synthesis, alignment, and applications. J Polym Sci B Polym Phys 2017;55:395-411.

[21] DiPasquale SA, Byrne ME. Controlled architecture for improved macromolecular memory within polymer networks. Curr Opin Biotechnol 2016;40:170-176.

[22] Peponi L, Navarro-Baena I, Kenny JM. Chapter 7: Shape memory polymers: properties, synthesis and applications. In: Smart polymers and their applications. Cambridge: María Rosa Aguilar and Julio San Román, Woodhead Publishing Limited (Elsevier); 2014. p. 204-236.

[23] Dawson R, Cooper AI, Adams DJ. Nanoporous organic polymer networks. Prog Polym 
Sci 2012;37:530-563.

[24] Upadhyay M, Kumar S, Adena R, Vardhan H, Yadav SK, Mishra B. Development of biopolymers based interpenetrating polymeric network of capecitabine: A drug delivery vehicle to extend the release of the model drug. Int J Biol Macromol 2018;115:907-919.

[25] Neamtu I, Rusu AG, Diaconu A, Nita LE, Chiriac AP. Basic concepts and recent advances in nanogels as carriers for medical applications. Drug Deliv 2017;24:539-557.

[26] Pohontu C, Popa M, Desbrieres J, Verestiuc L. Acrylates and methylcellulose based hydrogels. Synthesis, swelling properties and applications to inclusion and controlled release of bioactive matters. Cell Chem Technol 2016;50:609-620.

[27] Hoffman AS. Hydrogels for biomedical applications. Adv Drug Deliv Rev 2012;64:1823.

[28] Ganji F, Vasheghani-Farahani E. Hydrogels in controlled drug delivery systems theoretical description of hydrogel swelling. Iran Polym J 2009;18:63-88.

[29] a) Bouchaour T, Benmouna F, Coqueret X, Benmouna M, Maschke U. Swelling behaviour of isotropic Poly( $n$-butyl acrylate) networks in isotropic and anisotropic solvents. $\mathrm{J}$ Appl Polym Sci 2004;91:1-9.

b) Dali Youcef B, Bouchaour T, Maschke U. Phase Behavior of Poly( $n$-butyl acrylate) and Poly(2-ethylhexyl acrylate) in Nematic Liquid Crystal E7. Macromol. Symp. 2008; 273:6672.

c) Bedjaoui L, Berriah N, Boudraa K, Bouchaour T, Maschke U. Phase behavior of mixtures of low molecular weight nematic liquid crystals and photochemically crosslinked polyacrylates. Mol Cryst Liq Cryst 2010;526:119-129.

d) Bouchaour T; Bouberka Z, Dali Youcef B, Maschke U. Kinetic analysis of the swelling behavior of $\operatorname{poly}(n$-butylacrylate-1,6-hexanedioldiacrylate) networks in 4-cyano-4'-n-pentyl-biphenyl (5CB). J Appl Polym Sci 2017;134:45452. 
[30] Flory PJ. Principles of polymer chemistry. Ithaca: Cornell University Press;1953.

[31] a) Vendamme R, Bouchaour T, Pakula T, Coqueret X, Benmouna M, Maschke U. Effect of nematic order coupling on the phase diagrams of side-chain polymer gels with liquid crystal solvent. Macromol Mater Eng 2004;289:153-157.

b) Vendamme R, Bouchaour T, Pakula T, Maschke U. Swelling equilibria in mixtures of isotropic gels and low molar weight smectic-A liquid crystals. Colloids Surf A Physicochem Eng Asp 2007;295:113-122.

[32] Ferrell WH, Kushner DI, Hickner MA. Investigation of polymer-solvent interactions in poly(styrene sulfonate) thin films. J Polym Sci Polym Phys 2017;55:1365-1372.

[33] Hansen CM. The three dimensional solubility parameter-key to paint component affinities: I. Solvents, plasticizers, polymers and resins. J Paint Technol 1967;39:104-117.

[34] Hansen CM. Hansen Solubility Parameters: A User's Handbook. Second edition. Boca Raton: CRC press;2007.

[35] Hansen CM. The Universality of the Solubility Parameter. Ind Eng Chem Prod Res Dev $1969 ; 8: 2-11$.

[36] Fedors RF. A method for estimating both the solubility parameters and molar volumes of liquids. Polym Engin Sci 1974;14:147-154.

[37] Hildebrand JH, Scott RL. Solutions of nonelectrolytes. Annu Rev Phys Chem 1950;1:7592.

[38] Hildebrand JH, Scott RL. Regular solutions. Eaglewood Cliffs New York: Prentice Hall;1962.

[39] a) Gee G. Interaction between rubber and liquid. IV. Factors governing the absorption of oil by rubber, Trans Inst Rubber Ind 1943;18:266-281.

b) Gee G. The interaction between rubber and liquids. II. The thermodynamical basis of the swelling and solution of rubber. Trans Faraday Soc 1942;38:276-282. 
[40] a) Barton AFM. CRC Handbook of polymer-liquid interaction parameters and solubility parameters. Boca Raton: CRC press;1990.

b) CRC Handbook of chemistry and physics. $99^{\text {th }}$ edition. Boca Raton: CRC press;2018.

[41] Tager AA, Kolmakova LK. The solubility parameter, methods for its determination and its relationship with the solubility of polymers. Polym Sci USSR 1981;22:533-549.

[42] Lara J, Zimmermann F, Drolet D, Hansen CM, Chollot A, Monta N. The use of the Hansen solubility parameters in the selection of protective polymeric materials resistant to chemicals. Int J Curr Res 2017;9: 47860-47867.

[43] Brandt Nielsen T, Hansen CM. Elastomer swelling and Hansen solubility parameters. Polym Test 2005;24:1054-1061.

[44] Nelder JA, Mead R. A simplex method for function minimization. Comput J 1965;7:308313.

[45] Hansen CM. The Three dimensional solubility parameters and solvent diffusion coefficient. PhD Thesis, Copenhagen, Danish Technical Press;1967.

[46] Gharagheizi F. New procedure to calculate the Hansen solubility parameters of polymers. J Appl Polym Sci 2007;103:31-36.

[47] Vebber GC, Pranke P, Pereira CN. Calculating Hansen solubility parameters of polymers with genetic algorithms. J Appl Polym Sci 2013;131:1-12.

[48] Kwon S, Sung BJ. Effects of solvent quality and nonequilibrium conformations on polymer translocation. J Chem Phys 2018;149:244907.

[49] Mukherji D, Marques CM, Stuehn T, Kremer K. Depleted depletion drives polymer swelling in poor solvent mixtures. Nat Commun 2017;8:1374.

[50] Shi Q, Zhang K, Lu R, Jiang JW. Water desalination and biofuel dehydration through a thin membrane of polymer of intrinsic microporosity: atomistic simulation study. J Membrane Sci 2018;545:49-56. 
[51] Liu J, Xu Q, Jiang J. A molecular simulation protocol for swelling and organic solvent nanofiltration of polymer membranes, J Membrane Sci 2019;573:639-646. 